\title{
Surgical Management of Chronic Subdural Hematoma: Number of Burr Holes in Relation to Rate of Recurrence and Complications
}

\author{
AYMAN T. MAHMOUD, M.D.; HUSSEIN M. SOFFAR, M.D. and MOHAMED ADEL ELMALLAWANY, M.D. \\ The Department of Neurosurgery, Kasr Al-Ainy Faculty of Medicine, Cairo University
}

\begin{abstract}
Background: Chronic subdural hematoma (CSDH) is a common problem encountered in daily practice in neurosurgery departments worldwide. It is defined as abnormal collection of blood or blood product in the subdural space with an indolent course. The recurrence rate of $\mathrm{CSDH}$ ranges from $2 \%$ to $37 \%$.

Aim of Study: We tried to find if there a significance of the number of burr-holes in surgical evacuation of CSDH in relation to the rate of recurrence or the rate of complications.

Patients and Methods: This a prospective interventional study conducted over 32 patients with chronic subdural hematoma treated between January 2018 and January 2021. The patients were divided into 2 groups, 16 patients were operated by single burr-hole craniostomy (SBHC), and the other 16 patients were operated by double burr-hole craniostomy (DBHC). Recurrence was considered if there is need for re-evacuation of the hematoma surgically.
\end{abstract}

Results: Group A: This group included 16 patients operated by 2 burr holes. The only reported surgical complication in this group was superficial wound infection in 2 cases $(12.5 \%)$. Recurrence was reported in one case only (6.3\%). Group B: This group included 16 patients operated by single burr hole. Regarding the surgical complications: Superficial wound infection was reported in one case $(6.3 \%)$ and incomplete evacuation in one case $(6.3 \%)$. Recurrence was reported in 2 cases $(12.5 \%)$.

Conclusion: In our study, we found that the patients with CSDH operated upon by SBHC had higher rate of recurrence than those operated by DBHC, although it was not statistically significant $(p>0.05)$. There is no statistical significance regarding the rate of complication between both techniques. We conclude that surgical management of CSDH with SBHC is safe and efficient as DBHC.

Key Words: Chronic-Subdural-Hematoma-Burr-hole.

Correspondence to: Dr. Ayman T. Mahmoud, The Department of Neurosurgery, Kasr Al-Ainy Faculty of Medicine, Cairo University

\section{Introduction}

CHRONIC subdural hematoma (CSDH) is a common problem encountered in daily practice in neurosurgery departments worldwide [1,2]. The incidence of CSDH ranges from 1.72 to 20.6 per 100000 per year, with higher incidence in elderly population [3,4]. It is defined as abnormal collection of blood or blood product in the subdural space with an indolent course [3,5].

CSDH may be asymptomatic and discovered accidently with brain imaging. Manifestations of CSDH usually results from its expansion and compression of brain tissue. The manifestations may be only due to increased intracranial pressure as headache, seizure, mental status changes, nausea, and vomiting. More severe manifestations may occur due to brain compression such as weakness, impairment of conscious level or brain herniation in severe cases [3].

Usually a minor head trauma has been reported in history of patients presenting with CSDH, but negative history of head trauma is not uncommon [6]. Old age, anticoagulation or antiplatelet medications, alcohol intake and systematic diseases (liver or renal dysfunction) are considered risk factors of development of CSDH [3].

Asymptomatic cases managed conservatively wherever in symptomatic cases surgical evacuation is the mainstay of treatment [3,7]. Surgical evacuation is indicated also when the volume of the hematoma is significant with thickness $1 \mathrm{~cm}$ or more or if the hematoma is progressively increasing

\section{List of Abbreviations:}

CSDH: Chronic subdural hematoma.

SBHC: Single burr-hole craniostomy.

DBHC: Double burr-hole craniostomy. 
in thickness in follow-up imaging [8]. Surgical options of management of CSDH ranges from twist-drill craniostomy, burr-hole craniostomy (either single or double burr-holes), craniotomy and/or memberenectomy and endoscopic assisted evacuation $[\mathbf{7 , 9 , 1 0 ]}$.

Recurrence of CSDH may be radiological which is asymptomatic or may be symptomatic which requiring surgical intervention [10]. The recurrence rate of CSDH ranges from $2 \%$ to $37 \%[3,10,11]$.

In this study we tried to find if there a significance of the number of burr-holes in surgical evacuation of CSDH in relation to the rate of recurrence or the rate of complications.

\section{Patients and Methods}

This a prospective interventional study conducted over 32 patients with chronic subdural hematoma indicated for surgical evacuation treated between January 2018 and January 2021. Local ethical committee approval was obtained. The patients were divided into 2 groups, 16 patients were operated by evacuation of the hematoma by single burrhole craniostomy, and the other 16 patients were operated by double burr-hole craniostomy. Bilateral $\mathrm{CSDH}$ and recurrent cases was excluded from our study.

A detailed history was taken including age, gender, history of trauma, chronic medical diseases, alcohol intake, anticoagulation or antiplatelet medications, seizures, or previous operations. Meticulous examination was done for the patients including conscious level, motor power, speech, sensory affection, and cranial nerves.

Preoperative CT and MRI brain was obtained in all cases. Any anti coagulation was reversed preoperatively. Preoperative routine blood tests were done.

A subdural drain was inserted in all patients for intraoperative irrigation and drainage. Postoperatively the patients were confined to the bed with the head flat in the bed till removal of the drain. The drain was removed in all patients after 2 to 3 days.

All patients were followed-up clinically and radiologically. They evaluated clinically immediate postoperative and routinely for 4-6 weeks. Radiological postoperative evaluation was done by CT scan after one week of surgery then after one month or if there is recurrence of symptoms at any time. In our study recurrence was considered if there is need for re-evacuation of the hematoma surgically.

\section{Statistical analysis:}

Data was entered and statistically analyzed on the Statistical Package of Social Science Software program, version 25 (IBM SPSS Statistics for Windows, Version 25.0. Armonk, NY: IBM Corp.). Data was presented using mean and standard deviation for quantitative variables and frequency and percentage for qualitative ones. Comparison between groups for qualitative variables was performed using Chi square or Fisher's exact tests while for quantitative variables the comparison was conducted using student $t$-test. $p$-values less than or equal to 0.05 were considered statistically significant.

\section{Results}

This study included 32 patients presenting with CSDH between January 2018 and January 2021 divided in 2 groups.

Group A: This group included 16 patients operated by evacuation of the CSDH by 2 burr holes. The age of the patients in this group ranged from 36-74 years with mean $61.1 \pm 10.8$. There were 10 males $(62.5 \%)$ and 6 females $(37.5 \%)$ with male predominance. A minor old head trauma was reported as a predisposing cause in 6 patients (37.5\%), alcohol intake was reported in one patient $(6.3 \%)$, and in the other 9 patients $(56.3 \%)$ no other predisposing cause of the CSDH were reported. Administration of antiplatelet or anticoagulant medication was reported in 10 cases $(62.5 \%)$. Regarding to the associated chronic diseases: Hypertension was reported in 7 patients (43.8\%), diabetes mellitus in 5 patients $(31.3 \%)$, chronic renal failure in 3 patients $(18.8 \%)$, cardiac problems in 5 patients (31.3\%) and no associated chronic diseases were reported in 3 patients $(18.8 \%)$. In this group, 7 cases $(43.8 \%)$ presented with weakness, 3 cases (18.8\%) presented with disturbed conscious level, 2 cases presented with both weakness and disturbed conscious level, and 4 cases (25\%) presented with fits. The only reported surgical complication in this group was superficial wound infection in 2 cases (12.5\%). Recurrence of the CSDH was reported in one case only (6.3\%) in this group.

Group B: This group included 16 patients operated by evacuation of the CSDH by single burr hole. The age of the patient in this group ranged from 32-76 years with mean $63.1 \pm 10.2$. There were 10 males $(62.5 \%)$ and 6 females (37.5\%) with male predominance. A minor old head trauma was reported as a predisposing cause in 8 patients $(50 \%)$, and in the other 8 patients (50\%) no other predisposing causes of the CSDH were reported. Admin- 
istration of antiplatelet or anticoagulant medication was reported in 11 cases (68.8\%). Regarding to the associated chronic diseases: Hypertension was reported in 9 patients $(56.3 \%)$, diabetes mellitus in 7 patients $(43.8 \%)$, chronic renal failure in 5 patients $(31.3 \%)$, cardiac problems in 2 patients $(12.5 \%)$ and no associated chronic diseases were reported in one patient $(6.3 \%)$. In this group, 10 cases $(62.5 \%)$ presented with weakness, 1 case (6.3\%) presented with disturbed conscious level, and 5 cases $(31.3 \%)$ presented with fits. Regarding the surgical complications in this group: superficial wound infection was reported in one case $(6.3 \%)$ and incomplete evacuation in one case $(6.3 \%)$. Recurrence of the CSDH was reported in 2 cases $(12.5 \%)$ in this group. A comparison between both groups is summarized in Table (1).

Table (1): Comparison between both groups.

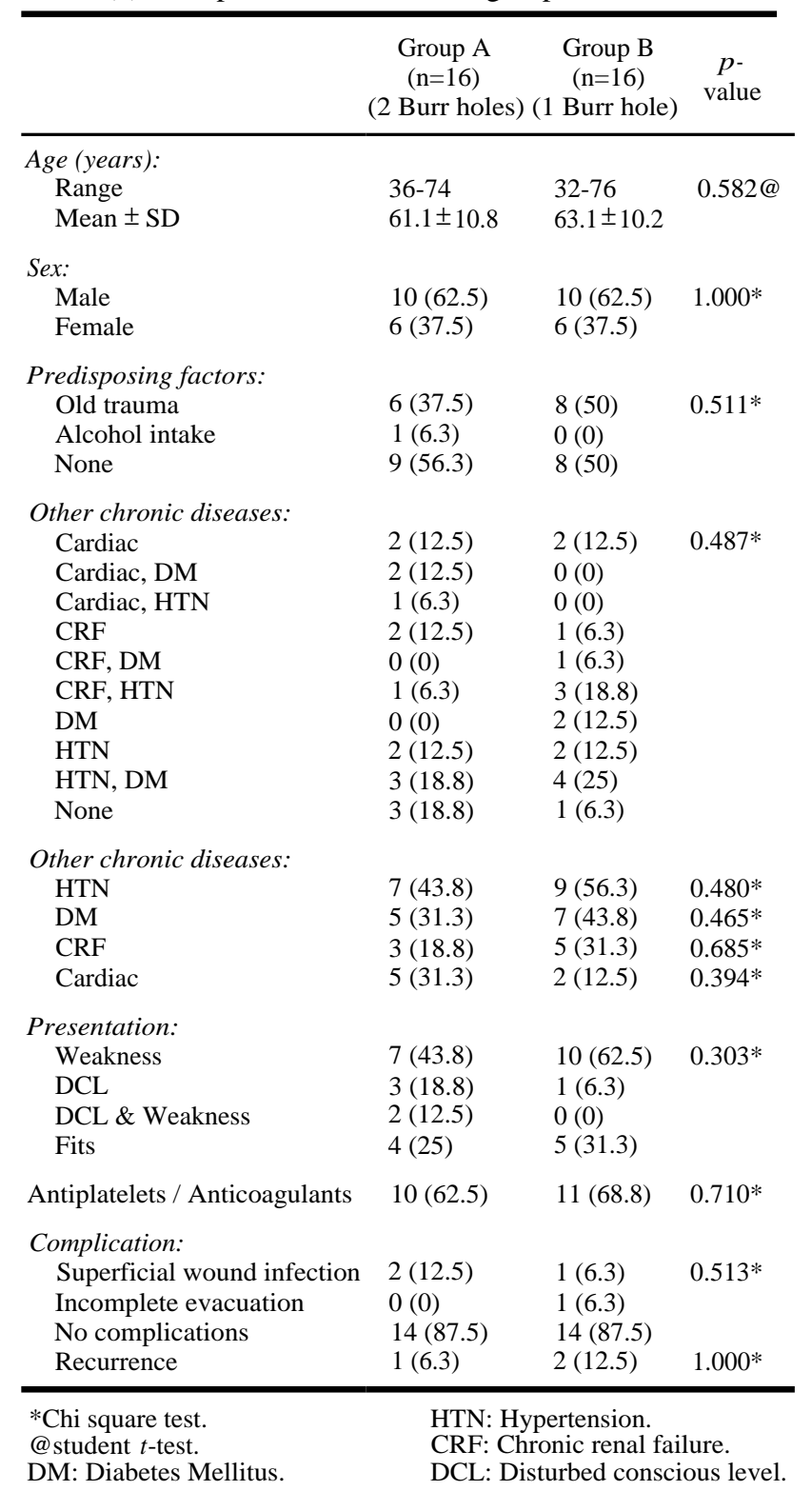

\section{Discussion}

By reviewing literatures as reached to our knowledge, this study is one of the few prospective studies discussing the significance of the number of burr-holes in surgical evacuation of CSDH in relation to the rate of recurrence or the rate of complications.

Chronic subdural hematoma is a common neurosurgical problem commonly occurs in older patients with annually increasing incidence [12] The most common factors related to recurrence of CSDH reported in literatures include old age, history of trauma, alcohol abuse, bleeding disorders, brain atrophy, bilateral hematoma, higher hematoma density and postoperative air accumulation at site of hematoma [12]

Surgical options for management of CSDH include burr hole craniotomy (either single or double burr holes), twist drill craniostomy, craniotomy, and endoscopic burr hole [13]. There is no agreement among neurosurgeons about the ideal number of burr holes (single or double) in drainage of CSDH [14]. Some surgeons prefer single burr hole craniostomy (SBHC) as it is faster with one incision only but others believe that it is not sufficient to drain the hematoma and associated with higher risk of recurrence in comparison with double burr hole craniostomy (DBHC) [1]

Recurrence of CSDH was defined in literatures by the need for an additional intervention based on clinical neurological deterioration and/or radiological reaccumulating or increase in size of the hematoma in postoperative imaging. The rate of recurrence in CSDH ranges between 5-26\% after evacuation $[6,15]$.

Some literatures who prefer DBHC tried to explain the higher rate of recurrence in SBHC that in SBHC there is less irrigation and evacuation of hematoma that leads to higher concentration of vasogenic cytokines, inflammatory mediators, and fibrinolytic factors in the residual hematoma. And the complete evacuation (which is more available in DBHC) is related to decrease the rate of recurrence by decreasing the concentration of those substance in the residual hematoma [16]. So, they recommend if the surgeon select the SBHC he should do a wide burr hole and the dura must be opened and coagulated sufficiently and take a long time in irrigation [16].

In our study done over 32 patients with chronic subdural hematoma indicated for surgical evacuation treated between January 2018 and January 
2021. The patients were divided into 2 groups, 16 patients were operated by evacuation of the hematoma by single burr-hole craniostomy and the other 16 patients were operated by double burrhole craniostomy. The only reported surgical complication in DBHC group was superficial wound infection in 2 cases $(12.5 \%)$. Recurrence of the CSDH was reported in one case only $(6.3 \%)$ in this group. While in SBHC group superficial wound infection was reported in one case $(6.3 \%)$ and incomplete evacuation in one case $(6.3 \%)$. Recurrence of the CSDH was reported in 2 cases $(12.5 \%)$ in this group. We found no statistical difference between both groups regarding the rate of recurrence or complications.

By reviewing literatures, we found 2 metaanalysis studies supporting our results. A metaanalysis done in 2013 by Belkhair $\mathrm{S}$ et al comparing the recurrence rate between SBHC and DBHC in treating CSDH. In that meta-analysis they found no statistically significant difference between both procedures regarding the revision rate. The weakness in that meta-analysis was that it only included 5 studies all of which was retrospective observational cohort studies with no randomization or pairing between patient groups [7].

Another meta-analysis was published in 2019 by Wan Y et al., included 12 studes, only 3 of which were randomized controled trials. Some studies found statestical significance regarding the recurrence rate with SBHC and others support the opposite oppenion. But in conclusion they found no statestical significance between SBHC and DBHC regarding the recurrence rate, morbidity, and complication rate. And conclude that SBHC is as safe and effective as DBHC in surgical management of CSDH [1]

A study published by Taussky $\mathrm{P}$ et al., in 2008 [2] was one of the studies favouring the DBHC and was included in both meta-analysis mentioned above. This was a retrospective study included 76 patients and conlude that SBHC for evacuation of $\mathrm{CSDH}$ leads to a significant higher rate of recurrence and complications with longer hospital stay. $\mathrm{He}$ explained that the high rate of recurrence is directly related to incomplete evacuation of the hematoma wich can be achieved better by the DBHC technique. And the more the residual hematoma, the more the concentration of fibrenolytic factors, vasoactive cytokines, and inflamatory mediators in the remaing hematoma fluid. And these substances are the main factores lead to recurrence of the CSDH [2]

\section{Conclusion:}

In our study, we found that the patients with CSDH operated upon by SBHC had higher rate of recurrence than those operated by DBHC, although it was not statistically significant $(p>0.05)$. There is no statistical significance regarding the rate of complication between both techniques. We conclude that surgical management of CSDH with SBHC is safe and efficient as DBHC.

\section{References}

1- WAN Y., XIE D., XUE Z., XIE J., SONG Z., WANG Y., et al.: Single Versus Double Burr Hole Craniostomy in Surgical Treatment of Chronic Subdural Hematoma: A Meta-Analysis. World Neurosurg [Internet], 131: e14954. Available from: https://doi.org/10.1016/j.wneu 2019.07.097, 2019.

2- TAUSSKY P., FANDINO J. and LANDOLT H.: Number of burr holes as independent predictor of postoperative recurrence in chronic subdural haematoma. Br. J. Neurosurg., 22 (2): 279-82, 2008.

3- YANG W. and HUANG J.: Chronic Subdural Hematoma: Epidemiology and Natural History. Neurosurg. Clin. N. Am. [Internet], 28 (2): 205-10. Available from: http://dx.doi.org/10.1016/j.nec.2016.11.002, 2017.

4- ASGHAR M., ADHIYAMAN V., GREENWAY M.W., BHOWMICK B.K. and BATES A.: Chronic subdural haematoma in the elderly - A North Wales experience. J. R Soc. Med., 95 (6): 290-2, 2002.

5- ALMENAWER S.A., FARROKHYAR F., HONG C., ALHAZZANI W., MANORANJAN B., YARASCAVITCH B., et al.: Chronic subdural hematoma management: A systematic review and meta-analysis of 34829 patients. Ann. Surg., 259 (3): 449-57, 2014.

6- MARTINEZ-PEREZ R., TSIMPAS A., RAYO N., CEPEDA S. and LAGARES A.: Role of the patient comorbidity in the recurrence of chronic subdural hematomas. Neurosurg Rev., 2020.

7- BELKHAIR S. and PICKETT G.: One versus double burr holes for treating chronic subdural hematoma metaanalysis. Can J. Neurol. Sci., 40 (1): 56-60, 2013.

8- MERSHA A., ABAT S., TEMESGEN T. and NEBYOU A.: Outcome of Chronic Subdural Hematoma Treated with Single Burr Hole Under Local Anesthesia. Ethiop J. Health Sci., 30 (1): 101-6, 2020.

9- SAHYOUNI R., MAHBOUBI H., TRAN P., ROUFAIL J.S. and CHEN J.W.: Membranectomy in Chronic Subdural Hematoma: Meta-Analysis. World Neurosurg [Internet], 104: 418-29. Available from: http://dx.doi.org/10.1016/ j.wneu.2017.05.030, 2017.

10- DESAI V.R., SCRANTON R.A. and BRITZ G.W.: Management of Recurrent Subdural Hematomas. Neurosurg. Clin. N. Am., 28 (2): 279-86, 2017.

11- MATSUMOTO H., HANAYAMA H., OKADA T., SAKURAI Y., MINAMI H., MASUDA A., et al.: Which surgical procedure is effective for refractory chronic subdural hematoma? Analysis of our surgical procedures 
and literature review. J. Clin. Neurosci. [Internet], 49: 40-7. Available from: https://doi.org/10.1016/j.jocn 2017.11.009, 2018.

12- HAN H.J., PARK C.W., KIM E.Y., YOO C.J., KIM Y.B. and KIM W.K.: One vs. two burr hole craniostomy in surgical treatment of chronic subdural hematoma. J. Korean Neurosurg Soc., 46 (2): 87-92, 2009.

13- SAHYOUNI R., GOSHTASBI K., MAHMOODI A., TRAN D.K. and CHEN J.W.: Chronic Subdural Hematoma: A Historical and Clinical Perspective. World Neurosurg. Dec., 108: 948-53, 2017.

14- KANSAL R., NADKARNI T. and GOEL A.: Single versus double burr hole drainage of chronic subdural hematomas.
A study of 267 cases. J. Clin. Neurosci Off J. Neurosurg. Soc. Australas. Apr., 17 (4): 428-9, 2010.

15- WATANABE S., KATO N., SATO M., AIYAMA H., FUJIWARA Y., GOTO M., et al.: Treatment Outcomes of Burr-Hole Surgery for Chronic Subdural Hematoma in the Elderly Living Beyond Life Expectancy: A Study Comparing Cure, Recurrence, and Complications in $\mathrm{Pa}-$ tients Aged > 80 Years versus $<79$ Years. World Neurosurg. Dec., 132: e812-9, 2019.

16- TOSAKA M., SAKAMOTO K., WATANABE S., YODONAWA M., KUNIMINE H., AISHIMA K., et al. Critical classification of craniostomy for chronic subdural hematoma; safer technique for hematoma aspiration. Neurol. Med. Chir. (Tokyo), 53 (4): 273-8, 2013.

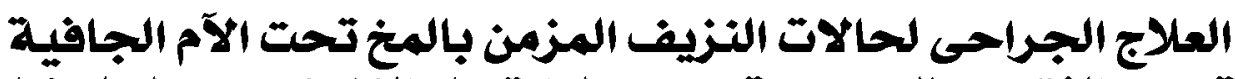

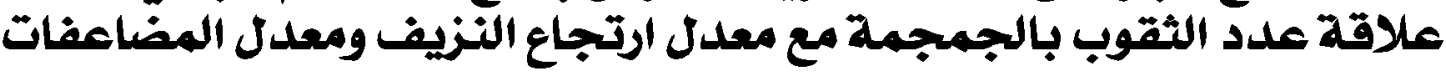

\author{
يعتبر النزيف المزمن بالمخ تحت الآم الجافية أحد أشهر الأمراض فى مجال جراحة المخ والأعصاب على هستوى العالم. يتراوح معدل

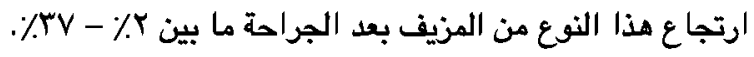 \\ حاولنا فى هذا البحث معرفة إذا كان هناك علاقة بين عدد الثقوب بالجمجمة مع معدل ارتجاع النزيف ومعدل المضاعفات.

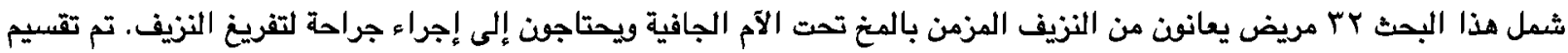

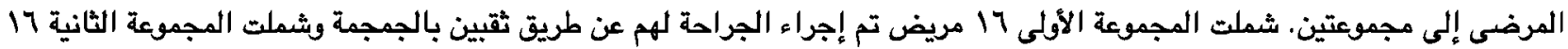

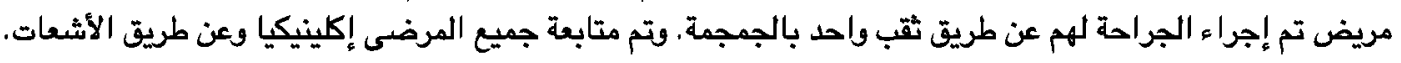

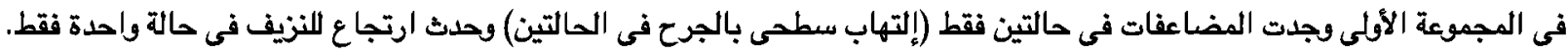

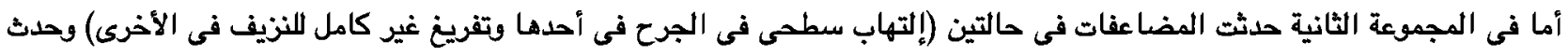 \\ ارتجاع للنزيف في حالتين. \\ في هذه الدراسة وجدنا إحمائياً أن تفريخ النزيف المزمن بالمخ تحت الأم الجافية جراحياً عن طريق ثقب واحد بالمجمجمة أمن وفعال \\ بالمقارنة بتقريغه جراحياً عن طريق ثقبين بالجمجمة.
}

